\title{
Efeito do uso de pentoxifilina no período neonatal sobre a produção espermática em ratos Wistar adultos
}

[Effect of pentoxifylline during neonatal period on spermatic production in adult Wistar rats]

T.A.P. Moraes, P.F. Jasset, S.M. Torres, A.V. Moraes, V.A. Silva Júnior*, M.M.P. Guerra

\author{
Universidade Federal Rural de Pernambuco \\ Av. Dom Manoel de Medeiros, s/n \\ 52171-900 - Recife, PE
}

\begin{abstract}
RESUMO
Utilizaram-se doses crescentes de pentoxifilina em ratos Wistar neonatos visando aumentar a produção espermática em animais adultos. Trinta e sete animais foram distribuídos de acordo com os tratamentos: não tratados $(\mathrm{n}=10)$ e tratados com $1 \mathrm{mg} / \mathrm{kg}(\mathrm{n}=10), 5 \mathrm{mg} / \mathrm{kg}(\mathrm{n}=9)$ e $10 \mathrm{mg} / \mathrm{kg}(\mathrm{n}=8)$ de pentoxifilina (IP). Aos 90 dias, os animais foram anestesiados e perfundidos intracardiacamente com solução fixadora. Os testículos foram processados rotineiramente para inclusão em resina plástica à base de glicol metacrilato. Cortes histológicos de $4 \mu \mathrm{m}$ de espessura foram corados em azul de toluidina/borato de sódio a $1 \%$ e analisados histometricamente. O número de células de Sertoli por secção transversal diminuiu nos grupos tratados com $5 \mathrm{mg} / \mathrm{kg}$ e $10 \mathrm{mg} / \mathrm{kg}$ em relação aos grupos controle e tratado com $1 \mathrm{mg} / \mathrm{kg}$. O índice de células de Sertoli aumentou nos animais tratados com $5 \mathrm{mg} / \mathrm{kg}$ em comparação aos do grupo-controle. A utilização da pentoxifilina não foi capaz de induzir aumento na população das células de Sertoli e produção espermática em ratos adultos.
\end{abstract}

Palavras-chave: rato, testículo, células de Sertoli, produção espermática, pentoxifilina

\begin{abstract}
Increasing doses of pentoxifylline were administrated to newborn Wistar rats in order to augment Sertoli cell number and sperm production in the adult rats. Thirty-seven neonate Wistar rats were distributed in four groups: control $(n=10)$ and treated with $1 \mathrm{mg} / \mathrm{kg}(\mathrm{n}=10), 5 \mathrm{mg} / \mathrm{kg}(\mathrm{n}=9)$, and $10 \mathrm{mg} / \mathrm{kg}(n=8)$ of pentoxifylline. At 90 days, the animals were submitted to anesthesia and intracardiac perfusion. Testes were colleted and routinely processed for inclusion in plastic resin with glycol methacrylate. Histological sections $(4 \mu \mathrm{m})$ were stained in toluidine blue/sodium borate (1\%) and analyzed. Number of Sertoli cell per transversal section of seminiferous tubule had significant reduction in the groups treated with $5 \mathrm{mg} / \mathrm{kg}$ and $10 \mathrm{mg} / \mathrm{kg}$ of pentoxifylline as compared to control and the group that received $1 \mathrm{mg} / \mathrm{kg}(P<0.05)$. The Sertoli cell index significantly increased in the group treated with $5 \mathrm{mg} / \mathrm{kg}$ compared to control group. Pentoxifylline did not cause increase in the number of Sertoli cells and daily sperm production in adult male rats.
\end{abstract}

Keywords: rat, testis, Sertoli cells, sperm production, pentoxifylline

\section{INTRODUÇÃO}

A proliferação das células de Sertoli e das células germinativas ocorre em diferentes períodos do desenvolvimento testicular, com momentos distintos para cada tipo celular. O número de células de Sertoli, estabelecido durante o período pré-púbere, determina o tamanho final do testículo e a produção espermática diária em animais sexualmente maduros (Orth et al., 1988; França et al., 2000).

Recebido em 3 de abril de 2008

Aceito em 27 de novembro de 2008

* Autor para correspondência (corresponding author)

E-mail: valdemiroamaro@bol.com.br 
Durante o período de imaturidade das células de Sertoli, o FSH (hormônio folículo estimulante) é o principal fator mitogênico responsável pela proliferação das células de Sertoli (Almiron e Chemes, 1988; Rocha et al., 1999). Assim, concentrações adequadas desse hormônio são necessárias para o estabelecimento da capacidade reprodutiva ideal em indivíduos adultos (Orth, 1988; Orth, 1993; Silva Junior, 2006).

As fosfodiesterases são enzimas que controlam a concentração intracelular de adenina monofosfato cíclico (AMPc) e guanina monofosfato cíclico (GMPc), funcionando como moduladores da resposta celular a hormônios (Conti et al., 1995; Conti, 2000). A pentoxifilina ou 1-(5-oxohexil)-3, 7-dimetilxantina é um inibidor inespecífico das fosfodiesterases, largamente prescrito nas desordens vasculares caracterizadas por deficiência na microcirculação regional (Salam et al., 2003; Ochiai et al., 2004). Por outro lado, a inibição de fosfodiesterases pode ser utilizada com o intuito de prolongar a estimulação hormonal sobre alguns tipos celulares, principalmente aqueles que geram AMPc ou GMPc (Conti, 2000).

Estudos in vitro indicaram que a pentoxifilina aumentou as concentrações de AMPc intracelular (Negri et al., 1996; Esteves et al., 1998; Tesarik et al., 2000; Stanic et al., 2002), simulando os efeitos do FSH na diferenciação e na sobrevivência de células germinativas in vitro e na capacidade de suporte das células de Sertoli em relação às células germinativas (Tesarik et al., 2000).

Este trabalho teve por objetivo avaliar o uso de doses crescentes de pentoxifilina, durante os primeiros 21 dias pós-natal, para aumentar a população de células de Sertoli e a produção espermática em ratos adultos.

\section{MATERIAL E MÉTODOS}

Foram utilizados 37 ratos neonatos Wistar (Rattus norvegicus, var. albinus) mantidos juntos com as mães, na temperatura $23 \pm 1^{\circ} \mathrm{C}$, em ciclo claro-escuro de 12 horas $^{1}$. Água e ração comercial foram oferecidos ad libitum até o final do experimento. Os ratos foram escolhidos por

${ }^{1}$ Aprovado pela Comissão de Ética - Parecer 04/2006 CEEA/DMFA. amostragem não probabilística de conveniência e submetidos aos diversos tratamentos, de acordo com o grupo experimental: controle $(n=10)$, $1 \mathrm{mg} / \mathrm{kg}(\mathrm{n}=10), 5 \mathrm{mg} / \mathrm{kg}(\mathrm{n}=9)$ e $10 \mathrm{mg} / \mathrm{kg}(\mathrm{n}=8)$ de pentoxifilina ${ }^{2}$.

Os tratamentos foram realizados durante os primeiros 21 dias pós-natal. A pesagem dos animais foi realizada diariamente para acompanhamento da curva de crescimento corporal e cálculo das doses de pentoxifilina, administradas via intraperitoneal. Aos 90 dias do período experimental, os ratos de cada grupo foram heparinizados (125UI/100g de peso corporal) e anestesiados por injeção intraperitoneal de tiopental sódico ${ }^{3}(30 \mathrm{mg} / \mathrm{kg})$ e submetidos à perfusão intracardíaca com solução fisiológica de $\mathrm{NaCl}$ a $0,9 \%$, acrescida de heparina sódica ${ }^{4}(500 \mathrm{UI} / \mathrm{L})$ e nitroprussiato de sódio $^{5}(100 \mathrm{mg} / \mathrm{L})$, por um período de 5 a 10 minutos. Após a lavagem do sistema vascular, os animais foram perfundidos com solução fixadora de glutaraldeído ${ }^{6}$ a $4 \%$, em tampão fosfato de sódio, $\mathrm{pH}$ 7,2 e 0,01M, durante 25 minutos.

Após a perfusão com solução fixadora, os testículos foram removidos, pesados e seccionados em fragmentos de até $2 \mathrm{~mm}$ de espessura e submetidos à refixação na mesma solução de perfusão. Para os estudos ao microscópio de luz, os fragmentos foram processados rotineiramente para inclusão em resina plástica à base de glicol metacrilato ${ }^{7}$. Cortes histológicos de $4 \mu \mathrm{m}$ de espessura foram corados em azul de toluidina/borato de sódio a $1 \%$ e analisados histometricamente.

O diâmetro tubular e a altura do epitélio foram medidos em aumento de $100 \mathrm{X}$ usando retículo micrométrico linear ${ }^{7}(10 \mathrm{~mm} / 100)$ calibrado com um micrômetro padrão. $\mathrm{O}$ diâmetro tubular médio para cada rato foi obtido a partir da mensuração de 15 túbulos, em diversos estágios do ciclo do epitélio seminífero, escolhidos aleatoriamente, com perfis redondos ou arredondados.

\footnotetext{
${ }^{2}$ Farmácia de Manipulação A Fórmula - Recife, Brasil.

${ }^{3}$ Roche Brasil - São Paulo, Brasil.

${ }^{4}$ Akzo Organon Teknika - São Paulo, Brasil.

${ }^{5}$ Sigma - St. Louis, EUA.

${ }^{6}$ Vetec - São Paulo, Brasil.

${ }^{7}$ Leica - Alemanha.
} 
A altura do epitélio foi obtida nos mesmos túbulos utilizados para determinar o diâmetro tubular. Para tal, tomaram-se duas mensurações diametralmente opostas, tendo como referência a túnica própria e o limite entre o lume e o epitélio germinativo, determinando-se, desta forma, a altura média do epitélio seminífero.

Os dados volumétricos da composição do parênquima testicular foram obtidos usando contagem de pontos por alocação sistemática de retículo micrométrico ${ }^{8}$ com 441 pontos de intersecção sobre a preparação histológica de testículo em aumento de 400X. Quinze campos foram contabilizados aleatoriamente somando um total de 6615 pontos para cada animal.

O volume de cada componente do testículo, expresso em microlitros, foi estabelecido a partir do produto entre a densidade volumétrica dos constituintes testiculares (\%) e o peso líquido do testículo $(\mathrm{mg})$. O valor deste último foi obtido pela subtração $6,5 \%$ da albugínea do peso testicular bruto (Russell e França, 1995). O comprimento total dos túbulos seminíferos (CT) por testículo (m) foi estimado a partir do conhecimento do volume ocupado pelos túbulos seminíferos no testículo e do diâmetro tubular médio obtido para cada animal. A seguinte fórmula foi empregada: $\mathrm{CT}=\mathrm{VTS} / \pi \mathrm{R}^{2}$, em que VTS $=$ volume total de túbulos seminíferos; $\pi R^{2}$ $=$ área da secção transversal dos túbulos seminíferos $(\mathrm{R}=$ diâmetro tubular/2) (Dorst e Sajonski 1974).

A estimativa dos diferentes tipos celulares que compõem o epitélio seminífero no estádio sete do ciclo, classificado de acordo com o método acrossômico (Russell et al., 1990), foi feita a partir de contagens dos núcleos das células germinativas, exceto de espermátides alongadas, e de nucléolos das células de Sertoli. Com exceção dos núcleos das células de Sertoli, as contagens obtidas foram corrigidas para o diâmetro nuclear e a espessura do corte histológico, utilizando-se a fórmula de Abercrombie (1946) modificada por Amann e Almiquist (1962). O diâmetro nuclear médio (DM) representa a média das medidas dos diâmetros de 10 núcleos do tipo celular estudado, para cada animal. Os diâmetros nucleares foram medidos com o auxílio de retículo micrométrico linear ${ }^{7}(10 \mathrm{~mm} / 100)$ adaptado a uma das oculares de $10 x$ e acoplado à objetiva de 100x, propiciando aumento final de 1000x. A população total de células de Sertoli por testículo foi obtida a partir do número corrigido de nucléolos de células de Sertoli por secção transversal de túbulo seminífero no estádio VII e do comprimento total de túbulos seminíferos por testículo, segundo a fórmula empregada por Hochereau-de Reviers e Lincoln (1978).

A produção espermática diária por testículo e por grama de testículo foi obtida de acordo com Silva Júnior et al. (2006). Os dados biométricos e histométricos foram expressos em média \pm desviopadrão. Foram realizadas análises de variância e teste Tukey para comparação de médias com nível de significância de $\mathrm{P}<0,05$.

\section{RESULTADOS E DISCUSSÃO}

$\mathrm{Na}$ Tab. 1 são apresentados os pesos corporal e testicular e o índice gonadossomático.

$O$ peso testicular dos animais tratados com $5 \mathrm{mg} / \mathrm{kg}$ foi $13,3 \%$ maior que o observado nos animais tratados com a maior dose $(10 \mathrm{mg} / \mathrm{kg})$. De acordo com França e Russell (1998), o peso testicular é altamente correlacionado com a produção espermática. Esta, por sua vez, apresenta relação direta com eventos decorridos durante o período crítico de desenvolvimento testicular em ratos (Orth et al., 1988). Portanto, mudanças experimentais induzidas durante este período podem aumentar ou diminuir o peso testicular e, consequentemente, a produção espermática (Silva Junior, 2000).

Até o momento, a administração da pentoxifilina durante o período crítico do desenvolvimento testicular não havia sido utilizada como metodologia para aumentar o peso dessa gônada. A dose de $5 \mathrm{mg} / \mathrm{kg}$ parece ter sido a mais adequada para obtenção do aumento do peso testicular, visto que a maior dose produziu efeito contrário ao que era esperado.

${ }^{8}$ Olympus - Tóquio, Japan. 
Tabela 1. Parâmetros biométricos de ratos Wistar aos 90 dias de idade, de acordo com os tratamentos (média \pm desvio-padrão)

\begin{tabular}{lccccc}
\hline \multicolumn{1}{c}{ Parâmetro } & $\begin{array}{c}\text { Controle } \\
(\mathrm{n}=10)\end{array}$ & $\begin{array}{c}1 \mathrm{mg} / \mathrm{kg} \\
(\mathrm{n}=10)\end{array}$ & $\begin{array}{c}5 \mathrm{mg} / \mathrm{kg} \\
(\mathrm{n}=9)\end{array}$ & $\begin{array}{c}10 \mathrm{mg} / \mathrm{kg} \\
(\mathrm{n}=8)\end{array}$ & \begin{tabular}{c}
$\mathrm{P}$ \\
\hline Peso corporal $(\mathrm{g})$
\end{tabular} \\
$359,30 \pm 22,6$ & $362,60 \pm 45,5$ & $388,90 \pm 31,5$ & $367,90 \pm 29,1$ & 0,2434 \\
Peso testicular $(\mathrm{g})$ & $1,66 \pm 0,10 \mathrm{ab}$ & $1,69 \pm 0,07 \mathrm{ab}$ & $1,79 \pm 0,11 \mathrm{a}$ & $1,57 \pm 0,17 \mathrm{~b}$ & 0,0058 \\
IGS (\%) & $0,46 \pm 0,04$ & $0,47 \pm 0,05$ & $0,46 \pm 0,05$ & $0,43 \pm 0,07$ & 0,4417 \\
\hline
\end{tabular}

Letras distintas na mesma linha indicam diferença entre valores pelo teste Tukey $(\mathrm{P}<0,05)$.

IGS (\%): índice gonadossomático.

A pentoxifilina é inibidora da fosfosdiesterase; em função disso, o efeito esperado é a ampliação da ação do AMPc. Este segundo mensageiro, na célula de Sertoli imatura, forma-se pela ligação do FSH com seu receptor de membrana ligado à proteína G (Tesarik et al., 2000). A dose de $10 \mathrm{mg} / \mathrm{kg}$ de pentoxifilina pode ter causado redução na formação de receptores de FSH ou mesmo promovido inativação desses (Griswold et al., 2001). Com isso, pode ocorrer redução na proliferação de células de Sertoli, o que justificaria a redução do peso testicular do grupo tratado com essa dosagem. O que se constatou foi apenas tendência de redução da população de células de Sertoli nos animais tratados com $10 \mathrm{mg} / \mathrm{kg}$ de pentoxifilina. Entretanto, o número dessas células estabelecido durante o período neonatal tem relação direta com a definição do peso testicular em ratos adultos (Silva Junior et al., 2006).

A volumetria do parênquima testicular expressa em microlitros é apresentada na Tab. 2. O peso líquido testicular teve redução significativa no grupo tratado com $10 \mathrm{mg} / \mathrm{kg}$ em relação ao grupo tratado com $5 \mathrm{mg} / \mathrm{kg}$, contudo, em nenhum dos grupos tratados com pentoxifilina, constatou-se relação de significância com o grupo-controle. Foi observado aumento no volume do túbulo seminífero e do epitélio seminífero no grupo de $5 \mathrm{mg} / \mathrm{kg}$ em relação aos grupos controle e tratado com $10 \mathrm{mg} / \mathrm{kg}$.

Tabela 2. Peso líquido do testículo $(\mu \mathrm{l})$, parâmetros volumétricos do parênquima testicular $(\mu \mathrm{l})$ de ratos Wistar, aos 90 dias de idade, de acordo com os tratamentos (média \pm desvio-padrão)

\begin{tabular}{lccccc}
\hline \multicolumn{1}{c}{ Parâmetros } & $\begin{array}{c}\text { Controle } \\
(\mathrm{n}=10)\end{array}$ & $\begin{array}{c}1 \mathrm{mg} / \mathrm{kg} \\
(\mathrm{n}=10)\end{array}$ & $\begin{array}{c}5 \mathrm{mg} / \mathrm{kg} \\
(\mathrm{n}=9)\end{array}$ & $\begin{array}{c}10 \mathrm{mg} / \mathrm{kg} \\
(\mathrm{n}=8)\end{array}$ & $\mathrm{P}$ \\
\hline Peso líquido & $1562,4 \pm 107,19 \mathrm{ab}$ & $1581,6 \pm 70,94 \mathrm{ab}$ & $1677,1 \pm 103,68 \mathrm{a}$ & $1473,0 \pm 163,39 \mathrm{~b}$ & 0,0079 \\
Túbulo seminífero & $1269,8 \pm 79,03 \mathrm{~b}$ & $1294,5 \pm 64,53 \mathrm{abc}$ & $1411,7 \pm 102,46 \mathrm{a}$ & $1209,9 \pm 181,53 \mathrm{bc}$ & 0,0056 \\
Epitélio seminífero & $1103,5 \pm 85,82 \mathrm{~b}$ & $1103,2 \pm 107,52 \mathrm{ab}$ & $1254,7 \pm 93,33 \mathrm{a}$ & $1044,8 \pm 157,39 \mathrm{bc}$ & 0,0031 \\
Lume & $89,60 \pm 41,69$ & $122,40 \pm 79,34$ & $89,33 \pm 23,91$ & $99,87 \pm 43,77$ & 0,4684 \\
Túnica própria & $76,80 \pm 16,58$ & $69,20 \pm 15,03$ & $68,00 \pm 11,06$ & $65,12 \pm 6,24$ & 0,2823 \\
Leydig & $34,00 \pm 7,21$ & $31,90 \pm 5,99$ & $28,89 \pm 7,44$ & $32,25 \pm 2,05$ & 0,3628 \\
Conjuntivo & $36,70 \pm 7,86 \mathrm{a}$ & $29,60 \pm 4,88 \mathrm{ab}$ & $24,67 \pm 6,65 \mathrm{~b}$ & $27,87 \pm 6,01 \mathrm{~b}$ & 0,0024 \\
Vaso sanguíneo & $62,40 \pm 3,56 \mathrm{a}$ & $59,20 \pm 6,81 \mathrm{ab}$ & $59,89 \pm 7,41 \mathrm{a}$ & $50,50 \pm 9,35 \mathrm{~b}$ & 0,0072 \\
Espaço linfático & $191,30 \pm 39,59$ & $197,20 \pm 51,28$ & $176,67 \pm 59,43$ & $180,00 \pm 48,61$ & 0,7941 \\
\hline
\end{tabular}

Letras distintas na mesma linha indicam diferença entre valores pelo teste Tukey $(\mathrm{P}<0,05)$.

Os túbulos seminíferos são constituídos por túnica própria (células mioides e membrana basal), epitélio germinativo ou seminífero e lume tubular (Karl e Capel, 1998). O compartimento tubular constitui a maior parte do testículo, ocupando, na maioria dos mamíferos de 70,0 a $90,0 \%$ da área, e o volume de túbulos seminíferos tem relação direta com parâmetros testiculares, como comprimento tubular, produção espermática e população de células de Sertoli (França e Russell, 1998). Desse modo, a dose de $5 \mathrm{mg} / \mathrm{kg}$ de pentoxifilina, administrada durante o período crítico do desenvolvimento testicular, influenciou positivamente a densidade volumétrica $(\%)$ e o volume de túbulos seminíferos $(\mathrm{P}<0,05)$, e a de $10 \mathrm{mg} / \mathrm{kg}$ mostrou-se ineficiente para modificar os parâmetros descritos anteriormente.

No volume do parênquima testicular alocado ao tecido conjuntivo, observou-se redução significativa nos grupos de 5 e $10 \mathrm{mg} / \mathrm{kg}$ de pentoxifilina $(\mathrm{P}<0,05)$. $\mathrm{Na}$ volumetria dos vasos sanguíneos do grupo de $10 \mathrm{mg} / \mathrm{kg}$, observou-se 
redução em relação aos grupos controle e tratado com $5 \mathrm{mg} / \mathrm{kg}(\mathrm{P}<0,05)$. A redução do volume de tecido conjuntivo pode estar relacionada ao poder antifibrogênico exercido pela pentoxifilina. Estudos in vitro demonstraram que essa metilxantina é um potente redutor da proliferação de fibroblastos, estimula a atividade de colagenases intersticiais e suprime a síntese, a secreção e a deposição de colágeno I e III, bem como de proteoglicanas e fibronectina (Raetsch et al., 2002). Além disso, LIN et al. (2005) demonstraram que a atividade antifibrogênica da pentoxifilina está relacionada à poderosa capacidade inibitória do fator de crescimento do tecido conjuntivo (CTGF) por essa metilxantina.

O número de células de Sertoli por secção transversal de túbulo seminífero (nucléolo de célula de Sertoli) sofreu redução significativa nos grupos tratados com $5 \mathrm{mg} / \mathrm{kg}$ e $10 \mathrm{mg} / \mathrm{kg}$ em relação aos grupos controle e tratado com $1 \mathrm{mg} / \mathrm{kg} \quad(\mathrm{P}<0,05) \quad$ (Tab. 3). A utilização de pentoxifilina no período neonatal teve como proposta amplificar o efeito do FSH sobre as células de Sertoli por meio da inibição da PDE3 e 4 presentes nessas células (Swinnen et al., 1991), produzindo aumento desse tipo celular por secção transversal ou ao longo do túbulo seminífero. Entretanto, o fármaco teve efeito contrário ao esperado, reduzindo o número dessas células por secção transversal. Segundo Jin et al. (1999), a manipulação farmacológica das fosfodiesterases in vivo pode alterar a diferenciação e a homeostase celular, o que produziria mais perda do que ganho funcional. Essa afirmação pode servir de suporte para justificar a redução na população de células de Sertoli por secção transversal de túbulo seminífero observado neste trabalho.

Tabela 3. Peso líquido do testículo, parâmetros biométricos do parênquima testicular $(\mu \mathrm{m})$, população de células de Sertoli, produção espermática diária por testículo (PED) e por grama de testículo (PED/g) em ratos Wistar aos 90 dias de idade, de acordo com os tratamentos (média \pm desvio-padrão)

\begin{tabular}{lccccc}
\multicolumn{1}{c}{ Parâmetro } & $\begin{array}{c}\text { Controle } \\
(\mathrm{n}=10)\end{array}$ & $\begin{array}{c}1 \mathrm{mg} / \mathrm{kg} \\
(\mathrm{n}=10)\end{array}$ & $\begin{array}{c}5 \mathrm{mg} / \mathrm{kg} \\
(\mathrm{n}=9)\end{array}$ & $\begin{array}{c}10 \mathrm{mg} / \mathrm{kg} \\
(\mathrm{n}=8)\end{array}$ & $\mathrm{P}$ \\
\hline Peso líquido do testículo $(\mathrm{mg})$ & $1562,4 \pm 107,2 \mathrm{ab}$ & $1581,6 \pm 70,9 \mathrm{ab}$ & $1677,1 \pm 103,7 \mathrm{a}$ & $1473,0 \pm 163,4 \mathrm{~b}$ & 0,0079 \\
Diâmetro tubular $(\mu \mathrm{m})$ & $305,1 \pm 19,7$ & $298,7 \pm 26,4$ & $300,7 \pm 25,6$ & $303,2 \pm 29,3$ & 0,9457 \\
Altura do epitélio $(\mu \mathrm{m})$ & $89,8 \pm 6,9$ & $88,0 \pm 7,6$ & $91,7 \pm 12,0$ & $93,3 \pm 8,5$ & 0,6223 \\
Sertoli/secção transversal de TS & $9,1 \pm 1,0 \mathrm{a}$ & $8,9 \pm 0,9 \mathrm{a}$ & $7,5 \pm 1,0 \mathrm{~b}$ & $7,7 \pm 0,6 \mathrm{~b}$ & 0,0007 \\
SPDAr/secção transversal & $62,4 \pm 3,3 \mathrm{ab}$ & $63,9 \pm 1,9 \mathrm{a}$ & $59,8 \pm 2,1 \mathrm{ab}$ & $59,3 \pm 5,7 \mathrm{~b}$ & 0,0223 \\
ICS & $6,9 \pm 0,8 \mathrm{~b}$ & $7,2 \pm 0,9 \mathrm{ab}$ & $8,0 \pm 1,0 \mathrm{a}$ & $7,7 \pm 0,8 \mathrm{ab}$ & 0,0450 \\
Comprimento total de TS $(\mathrm{m})$ & $17,8 \pm 2,7$ & $18,8 \pm 2,9$ & $20,2 \pm 3,6$ & $17,0 \pm 3,4$ & 0,1826 \\
Pop. cel. Sertoli $\left(\mathrm{x} 10^{7}\right)$ & $4,0 \pm 0,8$ & $4,1 \pm 0,5$ & $3,8 \pm 1,0$ & $3,3 \pm 0,8$ & 0,1365 \\
PED/testículo $\left(\mathrm{x} 10^{6}\right)$ & $20,8 \pm 3,3$ & $22,5 \pm 4,0$ & $22,4 \pm 4,2$ & $18,8 \pm 4,2$ & 0,1993 \\
PED/g/testículo $\left(\mathrm{x} 10^{6}\right)$ & $13,2 \pm 1,7$ & $14,2 \pm 2,3$ & $13,3 \pm 2,2$ & $12,9 \pm 2,9$ & 0,6258 \\
\hline Le
\end{tabular}

Letras distintas na linha indicam diferença entre valores $(\mathrm{P}<0,05)$; teste Tukey. TS = túbulo seminífero; ICS $=$ índice de célula de Sertoli; SPDar = espermátide arredondada.

As espermátides arredondadas por secção transversal apresentaram redução numérica significativa no grupo tratado com $10 \mathrm{mg} / \mathrm{kg}$ quando comparadas àquelas observadas nos animais tratados com $1 \mathrm{mg} / \mathrm{kg}(\mathrm{P}<0,05)$.

O índice de célula de Sertoli (ICS) apresentou diferença significativa entre os animais tratados com $5 \mathrm{mg} / \mathrm{kg}$ e o grupo-controle $(\mathrm{P}<0,05)$ (Tab. 3). Este índice reflete a eficiência funcional desta célula, como também a eficiência da produção espermática por unidade de área de túbulos seminíferos, expressa pela relação entre o número de espermátides alongadas, suportadas pelas células de Sertoli. Este aumento pode ser justificado nos animais do grupo tratado com
$5 \mathrm{mg} / \mathrm{kg}$ devido à redução significativa no número de células de Sertoli por secção transversal, no mesmo grupo. Além disso, a manutenção do número de espermátides arredondadas neste grupo em relação ao grupocontrole também justifica o aumento na capacidade de suporte das células de Sertoli.

O diâmetro tubular e a altura do epitélio seminífero refletem diferentes graus da atividade do epitélio, ocasionados por influência sazonal (Russell et al., 1994; Muñoz et al., 1998), pelo estabelecimento da puberdade (França e Cardoso, 1998), ou por efeitos deletérios da idade avançada (Nipken e Wröbel, 1997), de drogas bociogênicas (Kirby et al., 1996) e de 
hormônios gonadotróficos endógenos e exógenos (Swanlund et al., 1995), o que os tornam parâmetros importantes na avaliação quantitativa da espermatogênese, uma vez que existe correlação positiva entre o diâmetro tubular e a atividade espermatogênica do testículo (França e Russell, 1998). De acordo com França e Russell (1998), o diâmetro tubular médio não sofre alteração significativa após o estabelecimento da maturidade sexual e permanece aparentemente constante ao longo dos estádios do ciclo do epitélio seminífero em determinada espécie, mesmo ocorrendo variações expressivas, interespecíficas e raciais.

A altura do epitélio seminífero, na maioria de espécies domésticas, apresenta pequenas variações relacionadas à composição variada das associações celulares ou a possíveis alterações no volume das células de Sertoli, observada em diferentes estágios do ciclo do epitélio seminífero (França e Russell, 1998).

Quanto ao diâmetro tubular e à altura do epitélio seminífero, não se verificou alteração entre os grupos tratados e grupo-controle $(\mathrm{P}>0,05)$. A redução do número de células de Sertoli por secção transversal do túbulo seminífero nos grupos tratados com 5 e $10 \mathrm{mg} / \mathrm{kg}$ poderia acarretar diminuição nestes parâmetros. Entretanto, o aumento da capacidade de suporte das células de Sertoli e a manutenção do número de espermátides arredondadas, principalmente em relação ao controle, mantiveram a igualdade entre grupos experimentais quanto ao diâmetro e à altura de epitélio.

Não foi observado aumento significativo $(\mathrm{P}>0,05)$ do comprimento total de túbulos seminíferos nos animais tratados em relação aos do grupo-controle. Este parâmetro apresenta correlação direta e significativa com os pesos bruto e líquido testicular, volume de túbulo seminífero e epitélio seminífero, população de célula de Sertoli e produção espermática diária (França e Russell, 1998). É importante registrar a tendência de aumento do comprimento total de túbulos seminíferos e da produção espermática por testículo nas doses de 1 e $5 \mathrm{mg} / \mathrm{kg}$ de pentoxifilina. Os resultados de volume de túbulo e epitélio seminífero observados nos animais tratados com $5 \mathrm{mg} / \mathrm{kg}$ confirmaram a tendência observada nos parâmetros citados anteriormente, para este grupo.
O processo espermatogênico em ratos adultos não sofreu qualquer mudança quantitativa em função da aplicação neonatal da pentoxifilina. Isto se confirmou pela manutenção do rendimento intrínseco da espermatogênese, o qual é determinado pela produção espermática diária por grama de testículo $(\mathrm{PED} / \mathrm{g} / \mathrm{t})$, em que nenhum grupo diferiu do outro. De acordo com França e Russell (1998), a produção espermática diária por grama de testículo é utilizada como parâmetro de avaliação da eficiência da espermatogênese, que pode ser relacionada como menor duração da espermatogênese, maior número de células de Sertoli por grama de testículo e maior capacidade de suporte da célula de Sertoli, maior densidade volumétrica (\%) e volume dos túbulos seminíferos no testículo, maior número de gerações de espermatogônias e menor perda de células germinativas durante a espermatogênese.

Neste experimento, a proposta de se utilizar um inibidor inespecífico de PDE visou ampliar a duração intracelular dos níveis de AMPc e, por conseguinte, aumentar a proliferação de células de Sertoli. Entretanto, a aplicação do inibidor de fosfodiesterase, a pentoxifilina, em diferentes doses durante os primeiros 21 dias pós-natal em ratos, não alterou significativamente a população desse tipo celular.

Segundo França et al. (2000) e Silva Júnior et al. (2006), o número total de células de Sertoli define quantitativamente a PED/testiculo em um animal adulto. Portanto, os dados de população de células de Sertoli por testículo nos demais grupos deste experimento corroboram os dados obtidos para PED por testículo e por grama de testículo.

\section{CONCLUSÕES}

O emprego da pentoxifilina, nas dosagens utilizadas, durante o período crítico do desenvolvimento testicular neonatal em ratos Wistar, não foi capaz de induzir aumento na população das células de Sertoli. Por conseguinte, o uso desse fármaco nas doses utilizadas $(1,5,10 \mathrm{mg} / \mathrm{kg})$, visando aumentar a produção espermática e a eficiência da espermatogênese em ratos adultos, mostrou-se inviável. 


\section{REFERÊNCIAS BIBLIOGRÁFICAS}

ABERCROMBIE, M. Estimation of nuclear populations from microtome sections. Anat. Rec., v.94, p.238-248, 1946.

ALMIRÓN, I.; CHEMES, H. Spermatogenic onset. II. FSH modulates mitotic ativity of germ and Sertoli cells in immature rats. Int. J. Androl., v.11, p.235-246, 1988.

AMANN, R.P.; ALMQUIST, J.O. Reproductive capacity of dairy bulls. VIII. Direct and indirect measurement of testicular sperm production. $J$. Dairy Sci., v.45, p.774-781, 1962.

CONTI, M.; NEMOZ, G.; SETTE, C. et al. Recent progress in understanding the hormonal regulation of phosphodiesterases. Endocrinol. Soc., v.16, p.370-389, 1995.

CONTI, M. Phosphodiesterases and cyclic nucleotide signaling in endocrine cells. Mol. Endocrinol., v.14, p.1317-1327, 2000.

DORST, V.J.; SAJONSKI, H. Morphometrische untersuchunhen am tubulussystem des schweinehodens während der postnatalen entwicklug. Monatsh. Vet. Med., v.29, p.650$652,1974$.

ESTEVES, S.C.; SHARMA, R.K.; THOMAS, A.J. et al. Cryopreservation of human epermatozoa with pentoxifylline improves the post-thaw agonist-induced acrossome reaction rate. Hum. Reprod., v.13, p.3384-3389, 1998.

FRANÇA, L.R.; CARDOSO, F.M. Duration of spermatogenesis and sperm transit time through the epididymis in the piau boar. Tissue Cell, v.30, p.573-582, 1998.

FRANÇA, L.R.; RUSSELL, L.D. The testis of domestic mammals. In: MARTINEZ-GARCIA, F.; REGADERA, J. (Eds). Male reproduction: a multidisciplinary overview. Madrid: Churchill Comunications, 1998. p.198-219.

FRANÇA, R.L.; SILVA Jr., V.A.; CHIARINIGARCIA, $H$. et al. Cell proliferation and hormonal changes during postnatal development of the testis in the pig. Biol. Reprod., v.63, p.1629-1636, 2000.

GRISWOLD, M.D.; KIM, J.S.; TRIBLEY, W.A. Mechanisms involved in the homologus downregulation of transcription of the follicle- stimulating hormone receptor gene in Sertoli cells. Mol. Cell Endocrinol., v.28, p.95-107, 2001.

HOCHEREAU-DE REVIERS, M.T.; LINCOLN, G.A. Seasonal variation in the histology of the testis of the red deer, Cervus elaphus. J. Reprod. Fertil., v.54, p.209-213, 1978.

JIN, S.L., RICHARD, F.J., KUO, W.P. et al. Impaired growth and fertility of cAMP-specific phosphodiesterase PDE4D-deficient mice. Proc. Natl. Acad. Sci. USA., v.96, p.11998-12003, 1999.

KARL, J.; CAPEL, B. Sertoli cells of mouse testis originate from the coelomic epthelium. Dev. Biol., v.203, p.323-333, 1998.

KIRBY, J.D.; MANKAR, M.V.; HARDESTY, D. et al. Effects of transient prepubertal 6-Npropyl-2-thiouracil treatment on testis development and function in domestic fowls. Biol. Reprod., v.55, p.910-916, 1996.

LIN, S-L.; CHEN, R-H.; CHEN, Y-M. et al. Pentoxifylline attenuates tubulointerstitial fibrosis by blocking Smad3/4-activated transcription and profibrogenic effects of connective tissue growth factor. J. Am. Soc. Nephrol., v.16, p.2702-2713, 2005.

MUÑOZ, E.M.; FOGAL, T.; DOMINGUEZ, S. et al. Stages of the cycle of the seminiferous epithelium of the viscacha (Lagostomus maximul maximus). Anat. Rec., v.252, p.8-16, 1998.

NEGRI, P.; GRECHI, E.; TOMASI, A. Effectiveness of pentoxifylline in sêmen preparation for intrauterine insemination. Hum. Reprod., v.11, p.1236-1239, 1996.

NIPKEN, C.; WROBEL, K.H. A quantitative morphological study of age-related changes in the donkey testis in the period between puberty and senium. Andrologia, v.29, p.149-161, 1997.

OCHIAI, H.; ISHIDA, A.; OHTANI, T. et al. Discovery of new orally active phosphodiesterase (PDE4) inhibitors. Chem. Pharm. Bull., v.52, p.1098-1104, 2004.

ORTH, J.M.; GUNSALUS, G.L.; LAMPERTI, A.A. Evidence from Sertoli-cell depleted rats indicates that spermatid number in adults depends on numbers of Sertoli cells produced during perinatal development. Endocrinology, v.122, p.787-794, 1988. 
ORTH, J.M. Cell biology of testicular development in fetus and neonate. In: DESJARDINS, C.; EWING, L.L. (Eds). Cell and molecular biology of thet testis. New York: Oxford University, 1993. p.3-42.

RAETSCH, C.; JIA, J.D.; BOIGK, G. Pentoxifylline downregulates profibrogenic cytokines and procollagen I expression $\mathrm{n}$ rat secondary biliary fibrosis. Gut, v.50, p.241-247, 2002 .

ROCHA, D.M.C.; MIRANDA, J.R.; DEBELJUK, L. et al. Testis size, Sertoli cell population and daily sperm production in adult wistar rats treated neonatally with FSH and PTU. In: TESTIS WORKSHOP, 15., 1999, Louisville. The testis: from stem cell to sperm function. Norwell: Serono Symposia USA, 1999. p.60(II16)a.

RUSSELL, D.L.; ETTLIN, R.A.; SINHA HIKIM, A.P. et al. Mammalian spermatogenesis. In: RUSSELL, D.L.; ETTLIN, R.A.; SINHA HIKIM, A.P. (Eds). Histological and histopathological evaluation of the testis. Bolesta: Cache River, 1990. p.1-40.

RUSSELL, L.D.; SINHA-HIKIM, A.P.; GHOSH, S. et al. Structure-function relationships in somatic cells of the testis and accessory reproductive glands. In: BARTKE, A. A function of somatic cells in the testis. New York: Springer-Verlag, 1994. p.55-84.

RUSSELL, L.D.; FRANÇA, L.R.; HESS, R. et al. Characteristics of mitotic cells in developing and adult testes with observations on cell lineages. Tissue Cell, v.27, p.105-128, 1995.

SALAM, O.; BAIUOMY, A.R.; ELSHENAWY, S. et al. The anti-inflammatory effects of the Phosphodiesterase inhibitor pentoxifylline in the rat. Pharmacol. Res., v.47, p.331-340, 2003.

SILVA JÚNIOR, V.A. Efeitos da indução do hipotireoidismo e hipertireoidismo pós-natal na proliferação das células de Sertoli e na função testicular em suínos. 2000. 191f. Tese (Doutorado) - Instituto de Ciências Biológicas, Universidade Federal de Minas Gerais, Belo Horizonte.

SILVA JÚNIOR, V.A.; VIEIRA, A.C.S.; PINTO, C.F. et al. Neonatal treatment with naloxone increases the population of Sertoli cells and sperm production in adult rats. Reprod. Nutr. Dev., v.45, p.1-10, 2006.

STANIC, P.; SONICK, Z.; SUCHANEK, E. Effect of pentoxifylline on motility and membrane integrity of cryopreserved human spermatozoa. Int. J. Androl., v.25, p.186-190, 2002.

SWALUND, D.J.; N'DIAYE, M.R.; LOSETH, K.J. et al. Diverse testicular responses to exogenous growth hormone and folliclestimulating hormone in prepuberal boars. Biol. Reprod., v.53, p.749-757, 1995.

SWINNEN, J.V.; TSIKALAS, K. E.; CONTI, M. Properties and Hormonal Regulation of Two Structurally Related cAMP Phosphodiesterases from the Rat Sertoli Cell. J. Biol. Chem., v.266, p.18370-18377, 1991.

TESARIK, J.; MENDOZA, C.; GRECO, E. The effect of FSH on male germ cell survival and differentiation in vitro is mimicked by pentoxifylline but not insulin. Mol. Hum. Reprod., v.6, p.877-881, 2000. 